\title{
Measurements and Parametrizations of the Atmospheric Boundary-Layer Height at Dome C, Antarctica
}

\author{
Ilaria Pietroni · Stefania Argentini • Igor Petenko • \\ Roberto Sozzi
}

Received: 28 October 2010 / Accepted: 10 November 2011 / Published online: 1 December 2011

(C) The Author(s) 2011. This article is published with open access at Springerlink.com

\begin{abstract}
An experimental campaign, Study of the Atmospheric Boundary Layer Environmental at Dome C, was held during 2005 at the French-Italian station of Concordia at Dome C. Ground-based remote sensors, as well as in situ instrumentation, were used during the experimental campaign. The measurements allowed the direct estimation of the polar atmospheric boundary-layer height and the test of several parametrizations for the unstable and stable boundary layers. During the months of January and February, weak convection was observed while, during the polar night, a long-lived stable boundary layer occurred continuously. Under unstable stratification the mixing-layer height was determined using the sodar backscattered echoes and potential temperature profiles. The two estimations are highly correlated, with the mixing height ranging between 30 and $350 \mathrm{~m}$. A simple prognostic one-dimensional model was used to estimate the convective mixing-layer height, with the correlation coefficient between observations and model results being 0.66 . The boundarylayer height under stable conditions was estimated from radiosounding profiles as the height where the critical Richardson number is reached; values between 10 and $150 \mathrm{~m}$ were found. A visual inspection of potential temperature profiles was also used as further confirmation of the experimental height; the results of the two methods are in good agreement. Six parametrizations from the literature for the stable boundary-layer height were tested. Only the parametrization that considers the long-lived stable boundary layer and takes into account the interaction of the stable layer with the free atmosphere is in agreement with the observations.
\end{abstract}

Keywords Antarctic boundary layer $\cdot$ Boundary-layer height $\cdot$ Mini-sodar

\footnotetext{
I. Pietroni $(\varangle) \cdot S$. Argentini $\cdot$ I. Petenko Institute of Atmospheric Sciences and Climate, CNR, Via del Fosso del Cavaliere 100, 00133 Rome, Italy e-mail: ilaria.pietroni@artov.isac.cnr.it

I. Petenko

A.M.Obukhov Institute of Atmospheric Physics, RAS, Pyzhevskiy, 3, Moscow 119017, Russia

R. Sozzi

Environmental Protection Agency of Lazio Region (ARPA Lazio),

Via Boncompagni 101, 00187 Rome, Italy
} 


\section{Introduction}

The height of the atmospheric boundary layer $(\mathrm{ABL})$ is an important parameter for the $\mathrm{ABL}$ because it influences both the mean flow and the turbulent structure. Observations, parametrizations and model predictions of the ABL height have many theoretical and practical applications, especially in dispersion, climate and weather prediction models. The ABL height definition is more often chosen in the context of models and data availability rather than for physical reasons (Seibert et al. 2000); therefore several definitions of the ABL height can be found in the literature.

In studying the ABL height, stable and unstable stratifications must be considered separately due to differences in the turbulent processes occurring in the ABL. During daytime, thermal heating of the surface produced by insolation is the main source of turbulence, and convection produces the vertical mixing of energy and matter that is limited aloft by the presence of a stable layer. Under such conditions, a number of simple and reliable methods of measurement and of diagnostic and prognostic models are available for the determination of the unstable ABL height. During the night a surface-based temperature inversion develops due to surface radiative cooling and the production of turbulence is mainly due to wind shear, with buoyancy forces acting to suppress turbulence. Under stable stratification, when the negative buoyancy forces prevail, the turbulence is generally weak and sometimes intermittent; consequently, a complete mixing is often not attained and the ABL height is more difficult to determine. The structure of the stable boundary layer can be further complicated by the presence, at different heights, of wave motions of different amplitude.

The diurnal behaviour of the ABL in Antarctica is modified from that at mid-latitudes because of the peculiar variation of the solar radiation reaching the surface. In addition, different phenomena must be considered at the coast, the escarpment, and the pole (Gera et al. 1998; King et al. 2006).

A regular daily $\mathrm{ABL}$ evolution, characterized by strong stability conditions during the night and convective activity around local midday, was observed in various experiments on the Antarctic plateau during the summer months (Mastrantonio et al. 1999; Argentini et al. 2005; Van As et al. 2005). Mastrantonio et al. (1999), using sodar, observed convective activity at Dome C during a 10-day experiment in summer 1998. At the same location, during a 2-month experiment that began in 1999, the presence of weak convective activity was confirmed (Argentini et al. 2000, 2003). Georgiadis et al. (2002) showed that, on average, approximately half of the energy available at the surface supports the sensible heat flux, ranging between 10 and $20 \mathrm{~W} \mathrm{~m}^{-2}$. A wind-speed maximum of about $4.5 \mathrm{~m} \mathrm{~s}^{-1}$ occurs when the convection is well developed; the surface-based inversion is eroded and a transfer of momentum from the upper levels toward the surface occurs. The mixing-layer height reaches, in some cases, $500 \mathrm{~m}$ (Argentini et al. 2005).

In winter, due to the lack of solar radiation, a strong ground-based temperature inversion persists continuously (e.g., Schwerdtfeger 1970) and a long-lived stable layer (hereafter LLSL) forms. The LLSL differs from the nocturnal stable layer observed at mid-latitudes due to the absence of the diurnal residual layer so that the stable layer is in direct contact with the free atmosphere (Zilitinkevich 2002). Due to these peculiarities, ABL height estimation, parametrization and modelling on the Antarctic plateau is even more problematic. In addition, the severe climate conditions characterizing the site enhance the difficulties in obtaining measurements with the needed resolution and accuracy and, therefore, tests of the parametrizations and models for the ABL height are rare, in particular for the LLSL.

Various methods to estimate the ABL height from ground-based remote sensors and radiosoundings can be found in the literature (e.g. Beyrich 1997; Seibert et al. 2000; 
Asimakopoulos et al. 2004; Emeis et al. 2008). The more frequently used methods are those that consider the backscattered echoes from sodars, or the aerosol content measured by lidars. Other methods use the wind and temperature profiles determined from radiosondes.

The aim of our study is to provide an experimental ABL height estimate for the unstable and stable cases on the Antarctic plateau, and to compare these estimates with theoretical predictions. In Sect. 2, the experimental setting and the instrumentation are described, and in Sect. 3, the methodologies to estimate the boundary-layer height from the experimental measurements, both in the unstable and stable cases are given and the results are shown. The summary and conclusions are given in Sect. 4.

\section{Site and Instrumentation}

The French-Italian base of Concordia $\left(74^{\circ} 06^{\prime} \mathrm{S}, 123^{\circ} 20^{\prime} \mathrm{E}\right)$ was built at Dome $\mathrm{C}$ in the eastern region of Antarctica (Fig. 1). Dome C lies on the Antarctic plateau at 3,233 m a.s.l.

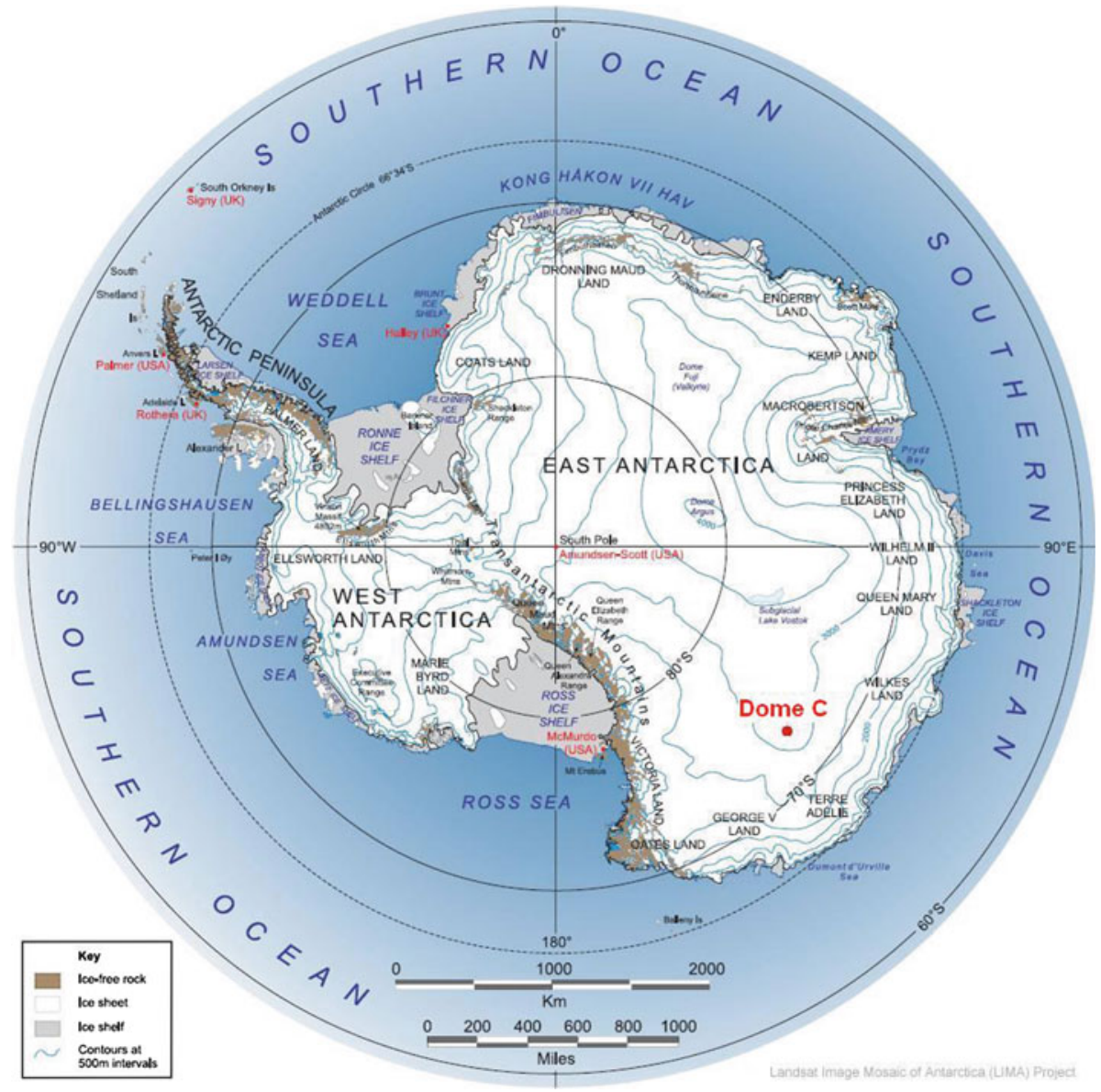

Fig. 1 A map of Antarctica showing the location of Concordia base at Dome $\mathrm{C}$ in the eastern sector of the continent (red point) 
Due to the flatness of this area, characterized by a slope $<1 \%$, and to the limited advection, the measurements collected at this base and the physical processes observed can be considered representative of a large area around.

An experimental campaign, STudy of the Atmospheric Boundary Layer Environmental at Dome C (STABLEDC), was held at Concordia from 20 December 2004 to 10 January 2006. The objective of the campaign was to study the processes occurring in the long-lived stable $\mathrm{ABL}$ and in the convective ABL observed during the winter and summer, respectively (Argentini et al. 2007). In order to avoid disturbances in measurements the experimental site was located 1,000 $\mathrm{m}$ south of the base, upwind in relation to the prevailing wind direction. In situ and ground-based remote sensors were used: a sonic thermo-anemometer (Metek USA-1) installed $3.6 \mathrm{~m}$ above the snow surface; a radiometer (Kipp and Zonen CNR-1) mounted $1 \mathrm{~m}$ above the snow surface; a heat flux plate (Campbell Scientific HFP01) at a depth of $50 \mathrm{~mm}$; a mini-sodar Doppler system; and a passive microwave radiometer (Meteorological Temperature Profiler, hereafter MTP 5-P). Radiosoundings were carried out twice each week from April 2005, in the framework of the Routine Measurements Observation programme (RMO, http://www.climantartide.it/).

During STABLEDC the averaged values of the meteorological parameters are comparable with the climatological values. In particular, the annual mean wind speed was $4.4 \mathrm{~m} \mathrm{~s}^{-1}$, with the extreme values observed during the winter. The main sector of the wind direction was $150-300^{\circ}$, coming from the pole, and associated with the strongest winds. The air-temperature behaviour during the year showed the typical seasonal cycle, characterized by the coreless winter typical of the Antarctic plateau (Stearns and Wendler 1988). The air temperature ranged between $-20^{\circ} \mathrm{C}$ (summer) and $-70^{\circ} \mathrm{C}$ (winter), with an annual mean value of $-45^{\circ} \mathrm{C}$. It is worth noting that during the summer both wind speed and temperature exhibit a clear diurnal cycle reaching maxima around midday. The same behaviour is also observed during spring and autumn, but the extent of variation between maximum and minimum values decreases, disappearing completely during the winter.

The sodar is a Doppler mini-sodar operating in a monostatic configuration. The emission frequencies were 3500,4000 and $4500 \mathrm{~Hz}$, the pulse duration $50 \mathrm{~ms}$, and the interval between two pulses $3 \mathrm{~s}$, allowing a vertical resolution of $14 \mathrm{~m}$ in the range between 16 and $400 \mathrm{~m}$.

The MTP 5-P is the polar version of a meteorological temperature profiler built by Attex and marketed by Kipp and Zonen (Kadygrov et al. 2001, 2003), differing from the previous system in its antenna dimensions. The use of a large antenna allows a resolution of $10 \mathrm{~m}$ in the first $50 \mathrm{~m}$ of the ABL, and a resolution of $50 \mathrm{~m}$ at $50 \mathrm{~m}$ and above. The range of measurements is $0-600 \mathrm{~m}$, the sampling period is $10 \mathrm{~min}$. The radiometer measures the brightness temperature and the atmospheric temperature profile is obtained using the retrieval algorithm described by Kadygrov and Pick (1998). The temperature at the first level is set to the temperature measured with an external thermometer.

The radiosoundings were carried out with Vaisala RS92 sondes, using the F-Thermocap temperature sensor (Jauhiainen and Lehmuskero 2005). Although the dimensions of the F-Thermocap sensor limit errors due to radiation and time lag, the construction company suggests the use of the correction proposed by Luers and Eskridge (1998). Considering that we analyze radiosounding profiles performed only during the polar night, the errors associated with solar radiation do not occur (Tomasi et al. 2006). Also the lag error can be neglected in the case of these radiosondes (Luers 1997).

The sonic anemometer, Metek USA-1, operated at a sample frequency of $10 \mathrm{~Hz}$, and the planar-fit method (Lee et al. 2004) was used to correct the measurements for possible errors due to sensor tilt. The turbulent characteristics, averaged over a period of $10 \mathrm{~min}$, were derived using the eddy-covariance technique (Lee et al. 2004). 


\section{Atmospheric Boundary-Layer Height Estimation}

Different definitions of ABL height can be found in the literature (COST Action 710 1998). Seibert et al. (2000) emphasize that the practical definitions of the ABL height often depend on available measurements rather than on theory, leading to many practical and theoretical problems in the evaluation and comparison of this parameter. For ABL height, also called mixing height, we use the general definition proposed in Beyrich (1997): "the mixing height is the height of the layer adjacent to the ground over which pollutants or any constituents emitted within this layer or entrained into it become vertically dispersed by convection or mechanical turbulence within a time scale of about an hour". In the practical use of this definition for the estimation of ABL height, the difference between unstable and stable cases should be considered.

Numerous methods have been proposed to determine the ABL height directly from measurements. In particular, remote sensing measurements and profiling techniques applied to radiosoundings profiles are widely used. Remote sensing techniques generally involve the use of sodar or lidar data. With radiosoundings, the profiles of parameters such as mixing ratio, potential temperature, pressure, humidity and wind are instead considered. In the next section, the experimental estimation of the convective mixing-layer height (hereafter $h_{\mathrm{ML}}$ ) and the LLSL height (hereafter $h_{\mathrm{SL}}$ ) are presented, and several parametrizations verified.

\subsection{Convective Mixing-Layer Height}

On the Antarctic plateau, the summer ABL is characterized by a diurnal cycle similar to that observed at mid-latitudes. When the amount of incoming solar radiation increases in the morning hours, a large fraction of the radiation is reflected due to the high albedo of the snow, yet the net radiation remains positive and the surface heats. An upward sensible heat flux enables a shallow convective boundary layer to form near the surface. This layer deepens gradually until the nocturnal inversion has been completely eroded; after that a rapid growth can be observed. The convective layer is capped by the so-called entrainment zone, and largescale vertical motions can have a considerable influence on the evolution of the mixed layer. When the solar elevation decreases, the available energy is small, so the thermally-driven turbulence decays and vertical mixing decreases.

As proposed by Brown and Hall (1979), the convective mixing-layer height can be determined from sodar measurements. A review of techniques and methods to estimate $h_{\mathrm{ML}}$ from sodar measurements can been found in e.g. Culf (1989), Beyrich and Weill (1993), Beyrich (1994, 1997), Argentini et al. (1996), Gera et al. (1998), Asimakopoulos et al. (2004) and Emeis et al. (2008). Following Argentini et al. (2005) we determined $h_{\mathrm{ML}}$ from the mini-sodar as the height of the first relative maximum in the backscattered echo intensity above a layer of well-developed convective activity. As an example the mini-sodar echogram of 27 January 2005, characterized by clear sky conditions and considered typical in respect to the behaviour of the main meteorological parameters, is shown in Fig. 2. The layer begins to develop at about 0700 LST (local standard time), grows until 1400 LST when it reaches its maximum height, and then decreases. The maximum echo intensity is clearly detectable in Fig. 2; the superimposed red dots represent the estimate of $h_{\mathrm{ML}}$, the error associated with the use of this method being estimated as $25 \mathrm{~m}$. The same technique was used for all the data collected during January and February. Discarding the days when the signal was absent or unclear for more than four hours, the observation period is reduced to a set of 44 days.

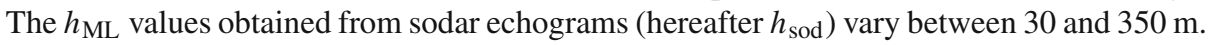
The values of $h_{\text {sod }}$ are chosen as a reference in the following experimental and modelled 

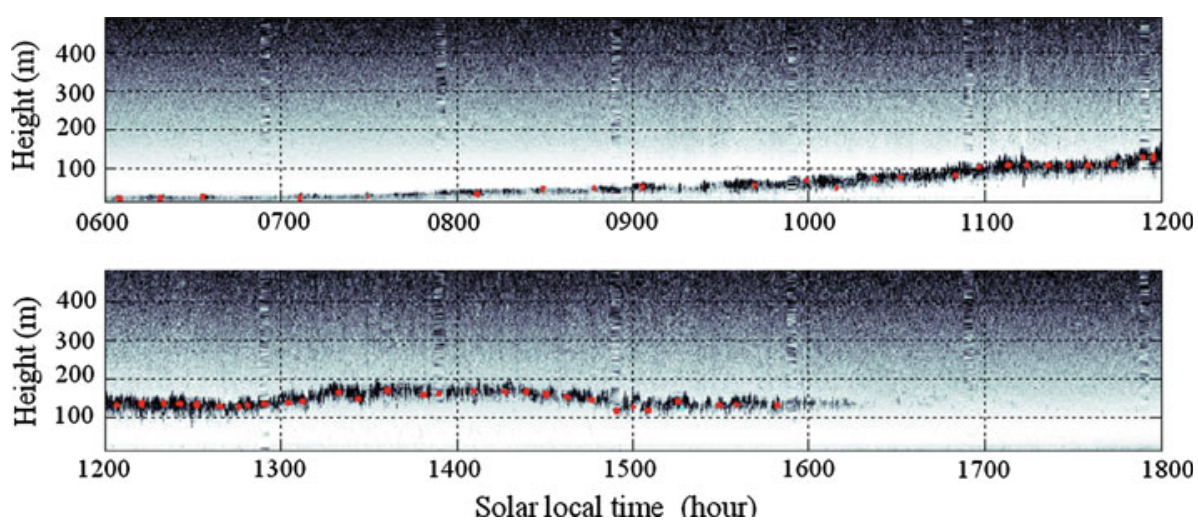

Fig. 2 Mini-sodar echogram for 27 January 2005, selected as typical behaviour of the mixing-layer development during the summer. The red dots represent the $h_{\mathrm{ML}}$ estimated as maximum echo intensity

determinations, because in convective conditions the sodar measurements provide a robust estimate of mixing-layer height.

Values of $h_{\mathrm{ML}}$ can also be determined from profiles of the main atmospheric variables such as temperature, humidity and wind, because these profiles, under convective conditions, show a characteristic behaviour. In particular, potential temperature profiles are characterized by an elevated inversion capping a layer with almost constant temperature (Stull 1988). Under these conditions, several objective methods have been developed. For example, Holzworth (1964) proposed a method, known as the parcel method, to determine $h_{\mathrm{ML}}$ as the equilibrium level of a hypothetical air parcel rising from surface. The influence of the surface temperature on this method has been corrected by the addition of an excess of temperature computed as $\delta \Theta_{\mathrm{v}}=C_{1} \overline{w^{\prime} \theta_{\mathrm{s}}^{\prime}}\left(u_{*}^{3}+C_{2} w_{*}^{3}\right)^{-1 / 3}$ (where $\overline{w^{\prime} \theta_{\mathrm{s}}^{\prime}}$ is the kinematic heat flux at the surface, $u_{*}$ is the friction velocity, $w_{*}$ is the convective velocity scale, and the constants $C_{1}=5, C_{2}=0.6$ ), as suggested by Holtslag et al. (1990). This improved parcel method, also known as the advanced parcel method, has been verified using the temperature profiles obtained with the MTP 5-P. The comparison between the $h_{\text {sod }}$ and $h_{\text {ML values obtained }}$ applying the advanced parcel method to the MTP 5-P profiles (hereafter $h_{\mathrm{mtp}}$ ) for 27 January 2005 is shown in Fig. 3. Considering the error attributed to $h_{\text {sod }}$, a substantial agreement can be noted throughout the day. In Fig. 4 , the scatter plot of $h_{\text {sod }}$ and of $h_{\text {mtp }}$ over the entire observation period is shown: the correlation coefficient between estimates is 0.80 , the root-mean-square error is $41 \mathrm{~m}$, and the mean difference is $14 \mathrm{~m}$.

The simple one-dimensional prognostic model proposed by Batchvarova and Gryning (1990) (hereafter GBmodel), was used to estimate $h_{\mathrm{ML}}$. The GBmodel is based on a parametrization of the turbulent kinetic energy budget within the mixing layer (assuming horizontal homogeneity), neglecting radiation and latent heat effects (Batchvarova and Gryning 1994). The derivation of the GBmodel is based on a zero-order scheme in which the entrainment zone is idealized as infinitesimally thin. The final practical and prognostic equation for the height evolution is (Gryning and Batchvarova 1990; Batchvarova and Gryning 1994):

$$
\left\{\left(\frac{h^{2}}{(1+A) h-2 B k L}\right)+\frac{C u_{*}^{2} T}{\gamma g[(1+A) h-B k L]}\right\}\left(\frac{\mathrm{d} h}{\mathrm{~d} t}-w_{\mathrm{s}}\right)=\frac{\overline{w^{\prime} \theta_{\mathrm{s}}^{\prime}}}{\gamma}
$$

where $k$ is the von Karman constant $(k=0.41), L$ is the Obukhov length, $T$ is the surface temperature, $g$ is the acceleration due to gravity, $\gamma$ is the potential temperature gradient in 


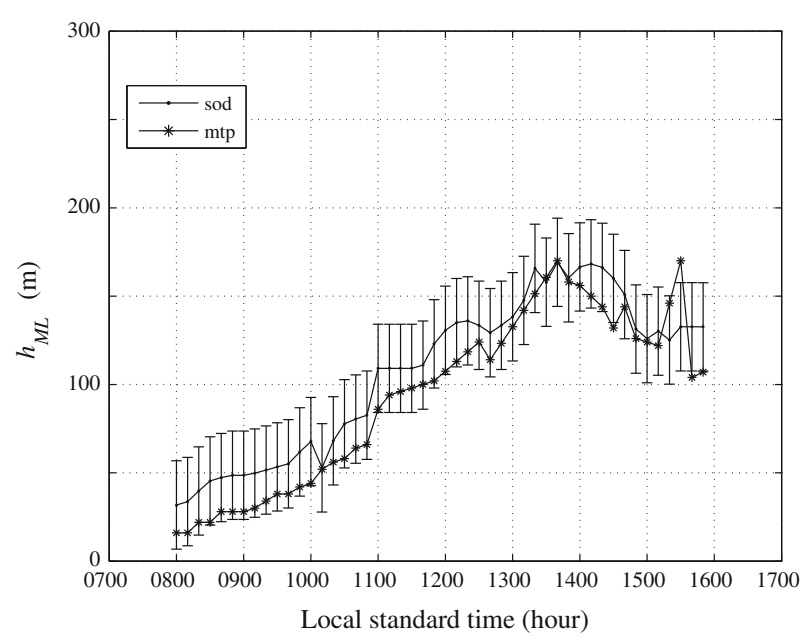

Fig. 3 Behaviour of $h_{\mathrm{ML}}$ for 27 January 2005 as estimated by mini-sodar (full black dots) and by the advanced parcel method using the profiles of MTP 5-P (starred black dots). An error bar is associated to the mini-sodar estimation

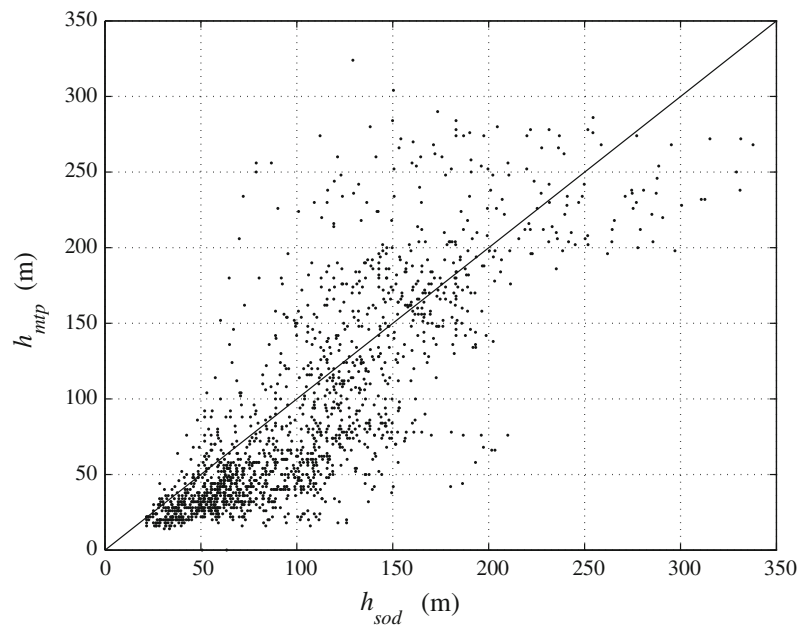

Fig. 4 Scatter plot comparing the $h_{\mathrm{ML}}$ estimated by mini-sodar $\left(h_{\mathrm{sod}}\right)$ and the advanced parcel method $\left(h_{\mathrm{mtp}}\right)$ for the entire observation period. The 1:1 line is full and black

the free atmosphere, $w_{\mathrm{s}}$ is the negative of the subsidence velocity, and $A, B, C$ are empirical constants set to $0.2,2.5$ and 8 , respectively, as in the original paper.

The first two terms on the left-hand side of Eq. 1 represent the entrainment due to buoyancy and mechanical turbulence, and the so-called spin-up effect, respectively. The latter is active during the morning when $h$ is small and its growth rate is controlled by the friction velocity. In the central part of the day this contribution decreases and the turbulent flux influences the development of the mixing layer (Gryning and Batchvarova 1990).

Equation 1 was solved numerically with the initial value of $h$ at $30 \mathrm{~m}$ and a time step of $10 \mathrm{~min}$. The computation begins just after sunrise when the kinematic heat flux becomes positive and remains positive without interruption until sunset. The turbulent parameters in 


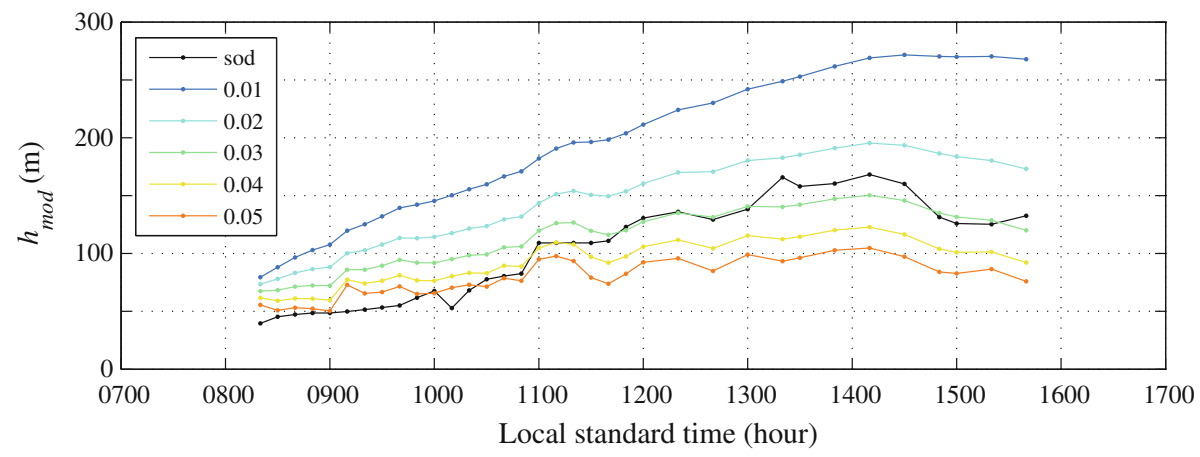

Fig. 5 Behaviour of $h_{\mathrm{ML}}$ for 27 January 2005 as estimated by mini-sodar (full black dots) and obtained using the GBmodel (full coloured dots). The colours refer to the different values of fixed $w_{\mathrm{s}}$ used and reported in the legend

Eq. 1 were obtained from the sonic anemometer measurements. As no radiosoundings were carried out during the summer 2005, $\gamma$ was derived from the temperature profiles measured by the radiosoundings at 1200 LST collected in a previous experiment at the same location and in the same period of the year. The values of $\gamma$, estimated considering a 100-m layer above the entrainment layer, ranged between 0.004 and $0.013 \mathrm{~K} \mathrm{~m}^{-1}$, the average value of $\gamma$ being $0.006 \mathrm{~K} \mathrm{~m}^{-1}$. The average value has been used, and kept fixed during the day. The subsidence $w_{\mathrm{s}}$ can be estimated if the horizontal divergence of the large-scale flow is known as a function of height; when the horizontal divergence is constant with height, the subsidence is proportional to the divergence. The latter can be estimated if wind measurements from a network of meteorological stations are available (Gryning and Batchvarova 1990). Due to the difficulties in estimating this value, the $w_{\text {s }}$ parameter is often neglected in Eq. 1. In shallow mixed layers, the omission of $w_{\mathrm{s}}$ is of minor importance in the entire range of meteorological conditions. However, during anticyclonic conditions, characterized by positive horizontal divergence, the downward directed subsidence velocity increases as the mixed layer evolves and may be of comparable magnitude to the rate at which the mixed layer entrains into the air aloft (Batchvarova and Gryning 1994). In these cases, $w_{\mathrm{s}}$ is negative and of the order of several tenths of $\mathrm{m} \mathrm{s}^{-1}$ (Gryning and Batchvarova 1999). Gryning and Batchvarova (1999) proposed to estimate $w_{\mathrm{s}}$ as the ratio between the potential temperature variation during the day, and the potential temperature gradient computed above the mixing layer. We applied this formulation to the layer between 500 and $600 \mathrm{~m}$, that is over the experimentally determined $h_{\mathrm{ML}}$. The comparison between $h_{\mathrm{ML}}$ estimated by the mini-sodar facsimile and computed using the GBmodel (hereafter $h_{\text {mod }}$ ), using a variable value for $w_{\mathrm{s}}$, and the $h_{\text {sod }}$ (not shown) shows a good correlation during the initial part of the day, but the results are poor after 1400 LST. Due to the difficulties in determining the correct values of $w_{\mathrm{s}}$, in most of the cases it is preferable to assign a fixed value to this parameter. To determine a reasonable value for $w_{\mathrm{s}}$, the GBmodel was initialized with different values in the range $0.01-0.05 \mathrm{~m} \mathrm{~s}^{-1}$, which were kept fixed during the day. The range of variability has been chosen considering the range of variability found with the method proposed by Gryning and Batchvarova (1999).

In Fig. 5, the behaviour of $h_{\text {sod }}$ and $h_{\text {mod }}$ with the values of $w_{\mathrm{s}}$ ranging between 0.01$0.05 \mathrm{~m} \mathrm{~s}^{-1}$ for 27 January 2005 is shown as an example. The model with fixed $w_{\mathrm{s}}$ simulates the $h_{\mathrm{ML}}$ evolution very well, especially during the first part of the day. A best-fit procedure was applied to the entire dataset in order to find a reliable value of $w_{\mathrm{s}}$, and the value that minimizes the difference between $h_{\text {sod }}$ and $h_{\text {mod }}$, is $0.04 \mathrm{~m} \mathrm{~s}^{-1}$. This value is in substantial 


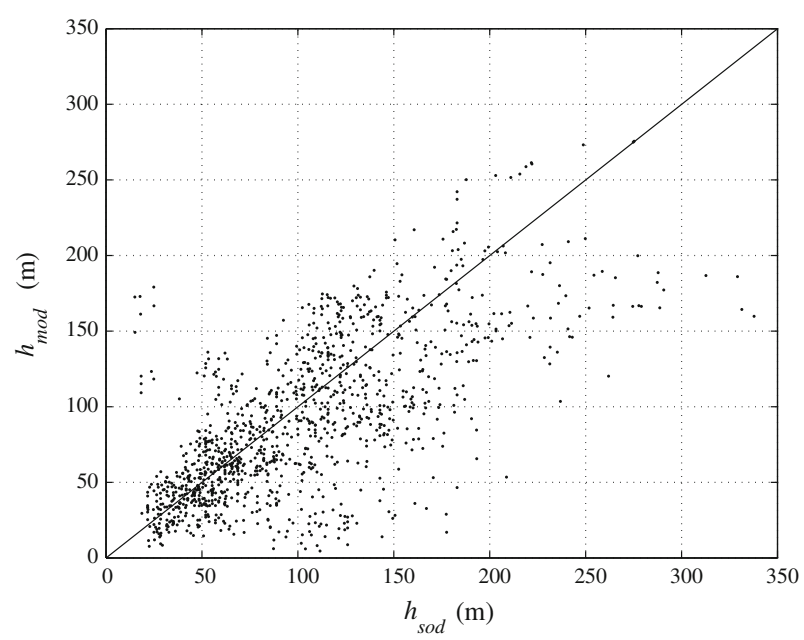

Fig. 6 Comparison between $h_{\mathrm{sod}}$ and $h_{\mathrm{mod}}$, computed with $w_{\mathrm{s}}=0.04 \mathrm{~m} \mathrm{~s}^{-1}$, for the entire dataset. A black line represents the bisector

agreement with the value of $w_{\mathrm{s}}=0.02 \mathrm{~m} \mathrm{~s}^{-1}$ found at Dome C by Argentini et al. (2005). Figure 6 shows the scatter plot between $h_{\text {sod }}$ and $h_{\text {mod }}$, implemented with $w_{\mathrm{s}}=0.04 \mathrm{~m} \mathrm{~s}^{-1}$ : the correlation coefficient is 0.66 , the mean difference is $15 \mathrm{~m}$ and the root-mean-square error is $43 \mathrm{~m}$.

\subsection{Stable Layer Height}

During the night, the boundary layer is stably stratified and a ground-based temperature inversion develops. For low wind conditions the largest temperature gradients occur near the surface, and the temperature decreases continuously with height. In these cases the determination of $h_{\mathrm{SL}}$ is difficult. When the mechanical production of turbulence increases, the potential temperature profile is often characterized by a linear increase near the surface, and a much smaller temperature gradient aloft. For strong winds and weak radiative cooling, a slight increase of the potential temperature with height is observed in the lowest layers. The lowest layer is capped by a shallow layer characterized by a stronger increase in the temperature, limited by a zone of weak stability. Consequently, under clear sky conditions and in moderate to high wind speeds, the stable layer is well defined, though in the other cases it can be shallow and intermittent and its height cannot be easily determined.

The vertical resolution of the mini-sodar used during STABLEDC did not allow the $h_{\mathrm{SL}}$ determination during the winter; in fact the echoes, if present, were always under the first range gate, and technical problems connected with reverberation made the reliable first range gate exceed $h_{\text {SL }}$ (Argentini et al. 2011). Due to the lack of reliable mini-sodar measurements during the winter, the vertical profiles obtained by radiosoundings have been used to determine $h_{\mathrm{SL}}$.

No universal relationships seem to exist between the profiles of temperature, humidity, wind speed, and the turbulence parameters for the stable ABL (COST Action 710 1998). For this reason various techniques involving the joint analysis of profiles of different variables are proposed to determine $h_{\mathrm{SL}}$. Due to the uncertainty in measuring $h_{\mathrm{SL}}$ by profiles, two methods were compared. 


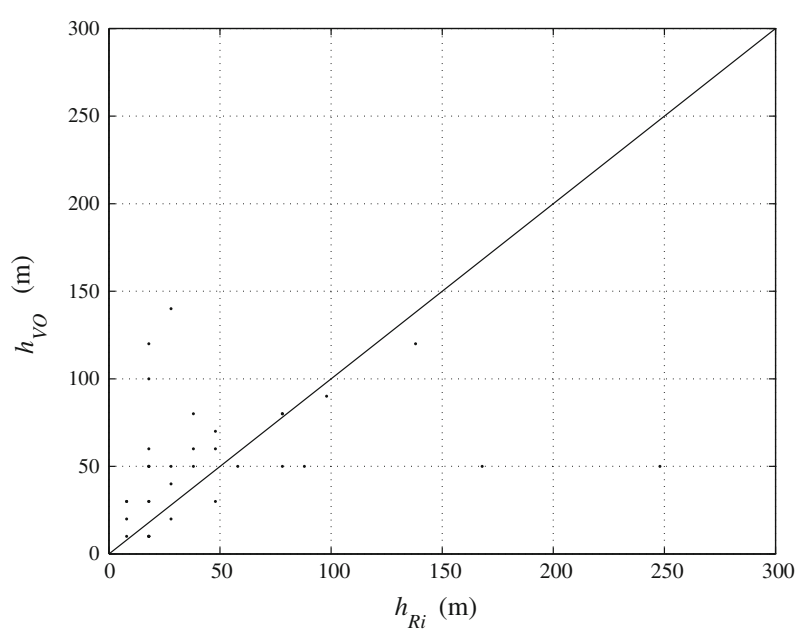

Fig. 7 Comparison between $h_{\mathrm{Ri}}$ and $h_{\mathrm{VO}}$. A black line represents the bisector

Firstly, $h_{\mathrm{SL}}$ was estimated using the bulk Richardson number, $R i$, computed from radiosoundings profiles (hereafter $h_{\mathrm{Ri}}$ ), as the height corresponding to a critical value of $R i=0.25$ (Holtslag et al. 1990). Because of the large gradient of $R i$ at the top of the turbulent layer, even if larger values of the critical $R i$ are used, no substantial variations occur in the estimate of $h_{\mathrm{Ri}}$. A second method consisted in the visual inspection of the potential temperature profiles to find the discontinuity between the layer close to the surface, characterized by a slight increase in the potential temperature, and the layer above characterized by a sharp increase of the potential temperature. The $h_{\mathrm{SL}}$ value determined through the visual observation method ( $h_{\mathrm{VO}}$ ) corresponds to the height of the layer closest to the ground.

During the Antarctic winter, warming events (Astapenko 1964) characterized by a sudden increase in the surface temperature (up to $30^{\circ} \mathrm{C}$ ) were observed. The warming events, lasting about 4-7 days and having a periodicity of about 10-15 days (Argentini et al. 2001), are generally accompanied by cloudiness, and/or advection of warm air and/or vertical mixing of air from different layers (Schwerdtfeger 1977; Carroll 1982; Stone et al. 1990; Stone and Kahl 1991; Stone 1993; Neff 1999; Petenko et al. 2007). In the presence of warming events the meteorological scenario is completely different from the stationary winter ABL and so these cases were excluded from the analysis.

For wind speeds $<5 \mathrm{~m} \mathrm{~s}^{-1} h_{\mathrm{VO}}$ could not be determined because the potential temperature profiles show a curvature continuously decreasing with height. The comparison between $h_{\mathrm{Ri}}$ and $h_{\mathrm{VO}}$ values is shown in Fig. 7. The values determined experimentally vary between 10 and $150 \mathrm{~m}$, the correlation coefficient is 0.8 and the mean difference is equal to $12 \mathrm{~m}$. The $R i$ method leads to slightly lower values than the visual observation method. The data points with differences between $h_{\mathrm{Ri}}$ and $h_{\mathrm{VO}}$ greater than $100 \mathrm{~m}$ have been considered anomalous and hence excluded in the following analysis (two profiles).

Most of the parametrizations available in the literature refer to the stable case, and $h_{\mathrm{SL}}$. Although these parametrizations use the surface turbulent measurements as input values, these may not be suitable for the LLSL. In the classical theory, $h_{\mathrm{SL}}$ depends on external parameters such as the Coriolis parameter $f$, the surface roughness length, and on turbulent parameters such as the surface friction velocity and the kinematic heat flux. The classical parametrizations listed in the second column of Table 1 were used to determine $h_{\mathrm{SL}}$. In the first column of Table 1 the names adopted for each parametrization used in the rest of the 
Table 1 Parametrizations for $h_{\mathrm{SL}}$

\begin{tabular}{llll}
\hline Name & Formulation & Constants & References \\
\hline Met1 & $h=\pi\left(2 k u_{*} z_{\mathrm{r}} / f\right)^{1 / 2}$ & $z_{\mathrm{r}}=1.25 \mathrm{~m}$ & Malcher and Kraus (1983) \\
Met2 & $h=c_{1} u_{*} / f$ & $c_{1}=0.14$ & Arya (1981) \\
Met3 & $h=c_{2} u_{*}(L / f)^{1 / 2}$ & $c_{2}=0.74$ & Arya (1981) \\
Met4 & $h=c_{*} u_{*}^{3 / 2}$ & $c_{*}=2.4 \times 10^{3}\left(\mathrm{~m}^{-1 / 2} \mathrm{~s}^{3 / 2}\right)$ & Venkatram (1980) \\
\hline
\end{tabular}

text are given, while the constants utilized and the references are reported in the third and fourth columns, respectively. The input parameters are the same as described in the previous paragraph, while $f=1.4 \times 10^{-4}$.

The formulation termed Met1, proposed by Malcher and Kraus (1983), is a closure equation of a dynamic integrated model. The basic assumption is that the boundary-layer height depends on the turbulent diffusion coefficient considered proportional to the friction velocity, and on the Coriolis parameter. The constant of proportionality proposed for stable conditions is reported in the third column of Table 1. Arya (1981) proposed the formulation Met2, originally used in the neutral case, for the stable regime, while in Met3, Arya (1981) also includes a dependence on $L$. Venkatram (1980), using a simple empirical equation linking $L$ to the square of the friction velocity, derived Met4 from Met3.

Zilitinkevich and Calanca (2000) proposed an advanced parameterization of $h_{\mathrm{SL}}$ for the LLSL. In this formulation the influence of the free atmosphere on the LLSL has been introduced through the Brunt-Vaisala frequency. As the LLSL occurs most of the time at Concordia during the winter, this formulation should be, in principle, the more appropriate. The relation proposed by Zilitinkevich (2002) is:

$$
\frac{1}{h^{2}}=\frac{f^{2}}{\left(C_{\mathrm{R}} u_{*}\right)^{2}}+\frac{|f| N}{\left(C_{\mathrm{CN}} u_{*}\right)^{2}}+\frac{\left|f B_{\mathrm{S}}\right|}{\left(C_{\mathrm{NS}} u_{*}^{2}\right)^{2}}
$$

where $N$ is the Brunt-Vaisala frequency, $B_{\mathrm{S}}$ the buoyancy flux at the surface defined as $\beta \overline{w^{\prime} T_{\mathrm{s}}^{\prime}}, \beta=g / T$ where $T$ is the surface absolute temperature.

The Brunt-Vaisala frequency was estimated using the potential temperature profiles obtained by radiosoundings as a bulk frequency in the range $400-1,200 \mathrm{~m}$; the mean value for the considered period is $N=(0.022 \pm 0.004) \mathrm{s}^{-1}$. This value, although high, is in agreement with that found by Coulter (1990), while Zilitinkevich and Calanca (2000) in West Greenland found $N$ values up to $10^{-1} \mathrm{~s}^{-1}$ during the polar night, and $3 \times 10^{-2} \mathrm{~s}^{-1}$ during the polar summer. The dimensionless empirical constants in Eq. 2 have been taken as equal to: $C_{\mathrm{R}}=0.6, C_{\mathrm{CN}}=1.36, C_{\mathrm{NS}}=0.51$, as suggested by Zilitinkevich et al. (2007).

Equation 2 includes three terms, each one considering a different degree of stability for $h_{\mathrm{SL}}$. The first term on the right-hand side represents the contribution of the truly neutral cases, the second term is a parametrization for the conventionally neutral regime, and the last term models the nocturnal stable boundary layer (Zilitinkevich and Calanca 2000).

The height $h_{\text {SL }}$ has also been calculated using the formulation proposed by Steenelveld et al. (2007), obtained by arranging the relevant parameters in the development of the stable layer, that is:

$$
h=L\left(\frac{\left|\frac{g}{T} \overline{w^{\prime} T_{\mathrm{s}}^{\prime}}\right|}{\alpha u_{*} f N L}\right)^{\lambda}
$$



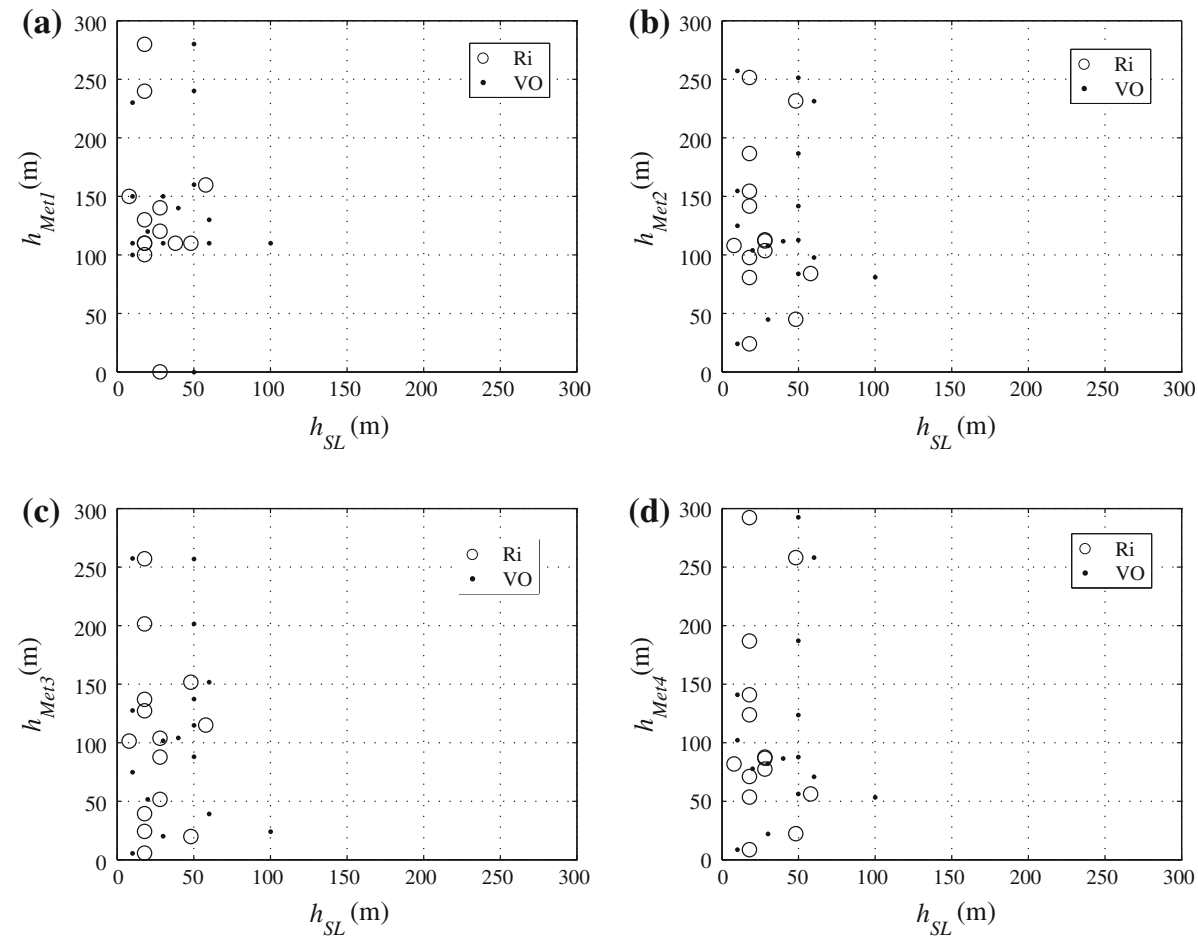

Fig. 8 Scatter plots between $h_{\mathrm{SL}}$ experimentally determined and parameterized using Met1 (a), Met2 (b), Met3 (c) and Met4 (d). In each box the open black dots represent the estimation made through the Richardson number, the full black dots are the estimates made using the visual observation method

where $\alpha=3$ and $\lambda=[1.8-0.001(N / f)]^{-1}$. The comparison between the experimental $h_{\mathrm{SL}}$ and the values obtained with the parametrization given in Table 1 and Eqs. 2 and 3 is shown in the scatter plots in Figs. 8 and 9, respectively. Figure 8a depicts the scatter plot between the experimental $h_{\mathrm{SL}}$ and $h_{\mathrm{SL}}$ obtained by Met1 $\left(h_{\mathrm{Met} 1}\right) ; h_{\mathrm{Met} 1}$ overestimates the values of $h$ determined from experimental data. Using Met2, the overestimation slightly decreases, but the correlation coefficient is less than 0.5 (Fig. 8b). A similar behaviour is observed considering Met 3 and Met 4 as shown in Fig. $8 \mathrm{c}$ and d. The $h_{\mathrm{SL}}$ value estimated using each of these parametrizations overestimates dramatically the values of $h_{\text {SL }}$ determined from experimental data. The scatter plots of $h_{\mathrm{SL}}$ measured and computed with the Eqs. $2, h_{\mathrm{Z}}$, and $3, h_{\mathrm{S}}$, are shown in Fig. 9a and b, respectively. In Eq. 2 the term representing the stable regime is dominant, leading to values of $h_{\mathrm{SL}}$ confined to the first $60 \mathrm{~m}$. Figure 9 a shows a correlation between experimental and calculated values: the correlation coefficient is 0.6 , the mean difference $13 \mathrm{~m}$ and the root-mean-square error $18 \mathrm{~m}$. The values found using Eq. 3, show a low correlation with experimental data and an overestimation greater than $100 \mathrm{~m}$ in all the cases (Fig. 9b).

Several previous definitions of $h_{\mathrm{SL}}$ were based on characteristics of mean wind and potential temperature profiles. In Yamada (1978) $h_{\mathrm{SL}}$ is defined as the top of the temperature surface inversion. This height (hereafter $h_{\mathrm{SI}}$ ) may be greater than $h_{\mathrm{SL}}$, particularly when the radiative cooling is relatively more important, namely in weak wind conditions (Krishna et al. 2003). 

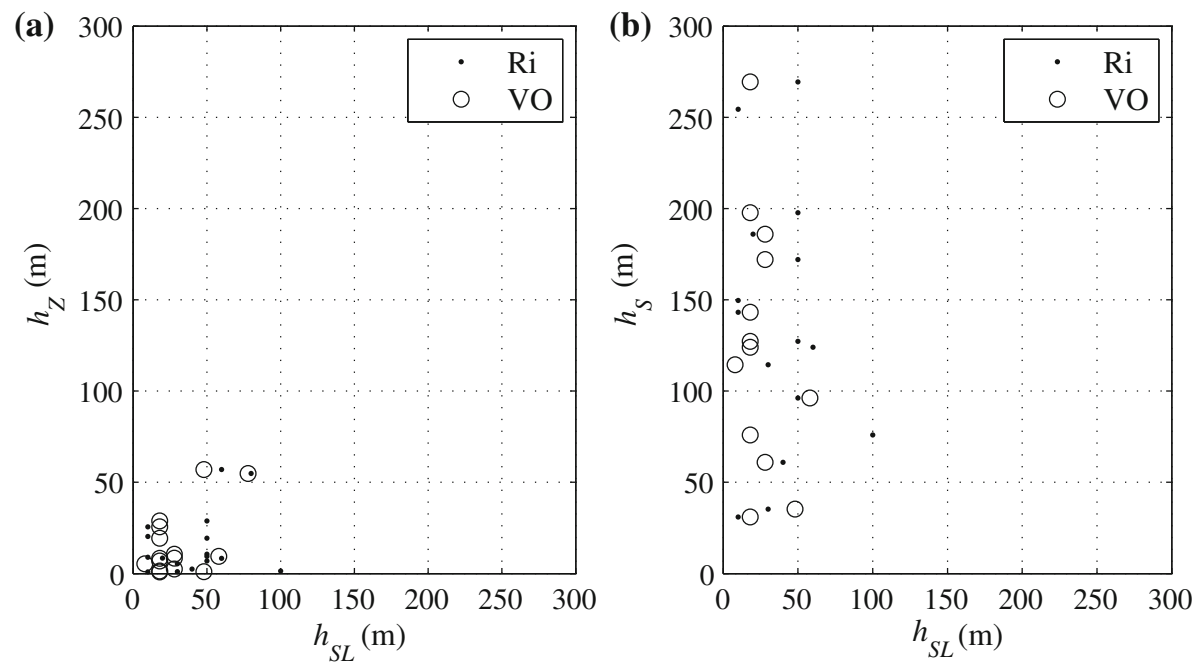

Fig. 9 Scatter plots between $h_{\mathrm{SL}}$ determined by experimental data and obtained using Eqs. 2 (a) and 3 (b). In each box the open black dots represent the estimates made through the Richardson number, the full black dots are the estimates made using the visual observation method

The parametrizations summarized in Table 1 were developed for mid-latitudes where the difference between $h_{\mathrm{SL}}$ and $h_{\mathrm{SI}}$ could be not relevant. The estimates of $h_{\mathrm{SL}}$ and $h_{\mathrm{SI}}$ may instead be different for the LLSL. In order to assess the possibility of using the parametrizations summarized in Table 1 to estimate $h_{\mathrm{SI}}$, a comparison between $h_{\mathrm{SL}}$ (parametrized) and $h_{\text {SI }}$ has been made. Here $h_{\text {SI }}$ was determined as the height where the potential temperature gradient becomes zero. An error of $25 \mathrm{~m}$ is associated with the measurements.

The results of the comparison between $h_{\mathrm{SI}}$ and $h_{\mathrm{SL}}$ estimated using the parametrizations listed in Table 1 and the parametrizations 2 and 3 are shown in Figs. 10 and 11, respectively. Comparing the parametrizations given in Table 1 and in Eq. 3 and $h_{\text {SI }}$, the correlation coefficients increase and the mean differences and root-mean-square errors decrease considerably in respect to $h_{\mathrm{SL}}$. Met1 shows a correlation of 0.6 with $h_{\mathrm{SI}}$ and mean difference values and a root-mean-square error greater than $60 \mathrm{~m}$ (Fig. 10a). The correlations obtained with Met2 and Met4, are 0.64 and 0.62, respectively (Fig. 10b, d). The use of Met3 implies knowledge of the kinematic heat flux that, being low, leads to an increase in the relative error. For this reason Met3 shows a lower correlation with $h_{\mathrm{SI}}$ in respect to Met4 (Fig. 10c, d). The correlation between $h_{\mathrm{Z}}$ and the estimate of $h_{\mathrm{SI}}$ is lower (Fig. 11a) than that with the experimental $h_{\mathrm{SL}}$. The spread of data between $h_{\mathrm{S}}$ and $h_{\mathrm{SI}}$ is comparable with that of the classical methods (Fig. 11b). Considering this behaviour, it is reasonable to use the parametrizations listed in Table 1 and Eq. 3 more as a proxy for the estimation of $h_{\mathrm{SI}}$ than as a method to estimate $h_{\mathrm{SL}}$.

\section{Summary and Conclusions}

The behaviour of the ABL height at Dome $\mathrm{C}$ was studied using a set of 1-year measurements from the STABLEDC field experiment. Its evolution was determined using groundbased remote sensing measurements from a mini-sodar and a microwave temperature profiler, 

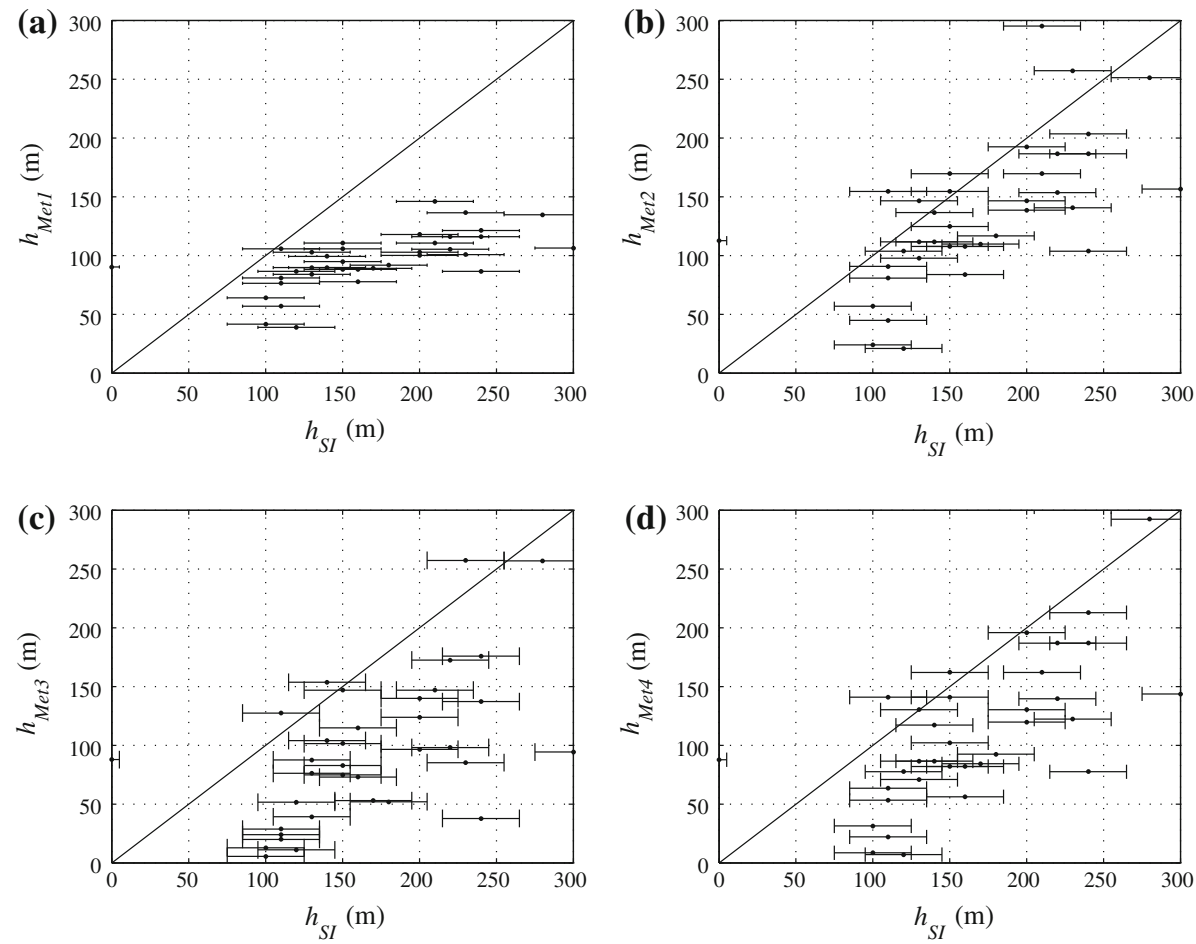

Fig. 10 Scatter plots between $h_{\text {SI }}$ determined using the experimental data and $h_{\text {SL }}$ parametrized using Met 1 (a), Met2 (b), Met3 (c) and Met4 (d). An error bar is associated to the $h_{\mathrm{SI}}$. In each box the full black line represents the bisector
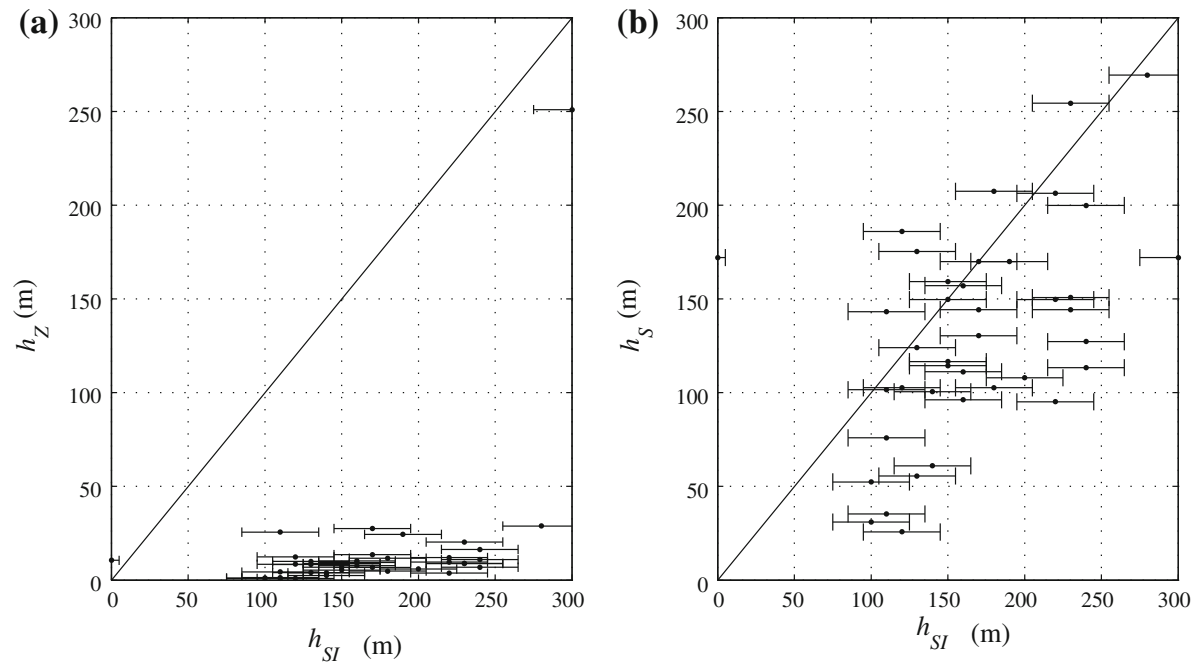

Fig. 11 Scatter plots between $h_{\mathrm{SI}}$ determined using the experimental data and $h_{\mathrm{SL}}$ parametrized using Eqs. 2 (a) and 3 (b). An error bar is associated to the $h_{\mathrm{SI}}$. In each box the full black line represents the bisector 
and vertical profiles obtained from radiosoundings. A simple prognostic model and several parametrizations found in the literature, were used to estimate the boundary-layer height, and the results compared with the direct estimates. The surface turbulent input parameters of both model and parameterizations were derived from the measurements using a sonic anemometer.

The summer convective mixing-layer height was estimated using the intensity of the mini-sodar backscattered echoes, and the temperature profiles from a microwave radiometer through the advanced parcel method. In January and February $h_{\text {sod }}$ and $h_{\text {MTP }}$ range between 30 and $350 \mathrm{~m}$ with the maximum reached at around $1400 \mathrm{LST}$. The estimates with the two methods have a correlation coefficient equal to 0.8 . The one-dimensional prognostic model proposed by Batchvarova and Gryning (1990) was used to estimate the evolution of convective mixing-layer height during the day. Although this model was developed to be used at mid-latitudes, the comparison with experimental data at Dome $\mathrm{C}$ is satisfactory, with a correlation coefficient of 0.66 .

The height of the LLSL, typical during wintertime, was estimated by radiosoundings profiles using two different methods. With the first method, $h_{\mathrm{SL}}$ was estimated as the height corresponding to a critical value (equal to 0.25 ) of the Richardson number. The second method consists of a case-by-case visual observation of the potential temperature profiles; $h_{\mathrm{SL}}$ is chosen as the point where the potential temperature profile has a clear discontinuity. The values found with the two methods range between 10 and $150 \mathrm{~m}$; the correlation coefficient is 0.8 . The Richardson number method generally gives lower values with respect to the visual observation method; the mean difference is $12 \mathrm{~m}$. On the other hand, no correlation and a systematic overestimation were found between the stable layer height determined from experimental data and the values estimated using the parametrizations for the stable boundary layer given in Table 1 and the formulation proposed by Steenelveld et al. (2007). A better correlation is obtained with the formulation proposed by Zilitinkevich (2002) for the LLSL. In this formulation the influence of the free atmosphere on the ABL is added. The correlation between the experimental boundary layer and the formulation proposed by Zilitinkevich (2002) is 0.6.

The parametrizations summarized in Table 1 and the formulation proposed by Steenelveld et al. (2007) show, however, a correlation with the height corresponding to the surface temperature inversion that does not necessarily correspond to the stable boundary-layer height.

The dataset used in this study for the winter season, is limited due to the use of radiosoundings that have been made only twice at week. In addition the method for the estimate of $h_{\mathrm{SL}}$, which implies the choice of a threshold in wind speed, further reduces the dataset and then the generality of the results. Sodar, which appears to be the instrument more suitable for determining the shallow Antarctic boundary layer in stable conditions because it allows a continuous and unmanned monitoring at relatively low cost, could not be used due to the limitation in the vertical range of measurements. To overcome this limitation a new mini-sodar, developed at the Institute of Atmospheric Sciences and Climate (Italy), will be used in a field experiment to commence in 2012. This new minisodar named SLM-sodar (Argentini et al. 2011), will permit the monitoring of the evolution of the stable boundary layer starting from the surface up to $150 \mathrm{~m}$ with a resolution of $1.7 \mathrm{~m}$.

Acknowledgments This research was supported by the Italian Antarctic Research Programme (PNRA) in the framework of the French-Italian "Dome C" project. The authors wish to thank the logistics staff at Concordia for their support during the experimental fieldwork, and thank Dr. A. Pellegrini and the RMO staff for providing radiosoundings at Concordia. A special thanks to Dr. G. Dargaud who over-wintered at Concordia station during 2005. The authors also wish to thank Dr. G. Mastrantonio, Dr. A. Viola and Mr. A. Conidi for their contributions in the realization of STABLEDC. 
Open Access This article is distributed under the terms of the Creative Commons Attribution Noncommercial License which permits any noncommercial use, distribution, and reproduction in any medium, provided the original author(s) and source are credited.

\section{References}

Argentini S, Mastrantonio G, Viola A, Pettré P, Dargaud G (1996) Sodar performances and preliminary results after one year measurements at Adelie coast, East Antarctica. Boundary-Layer Meteorol 81:75-103

Argentini S, Dargaud G, Mastrantonio G, Sempreviva AM, Viola A (2000) Study of the onset and evolution of the convective boundary layer observed at the Antarctic plateau station of Dome $\mathrm{C}$ using a mid-latitude mixing-height model. In: Bradley S (ed) Proceedings of the 10th international symposium on acoustic remote sensing and associated techniques of the atmosphere and oceans, Auckland, New Zealand, pp 172-175

Argentini S, Petenko I, Mastrantonio G, Bezverkhnii V, Viola A (2001) Spectral characteristics of East Antarctica meteorological parameters during 1994. J Geophys Res Atmos 106:12463-12476

Argentini S, Mastrantonio G, Viola A, Nardino M, Petenko IV, Sempreviva AM (2003) PBL height behaviour at the plateau site of Dome C, Antarctica: sodar observations and numerical estimates. In: Colacino M (ed) Proceedings of the 9th workshop Italian research on Antarctic atmosphere, Rome, Italy, 80, pp 13-26

Argentini S, Viola A, Sempreviva AM, Petenko I (2005) Summer boundary-layer height at the plateau site of Dome C, Antarctica. Boundary-Layer Meteorol 115:409-422

Argentini S, Pietroni I, Mastrantonio G, Viola A, Petenko I (2007) Atmospheric boundary layer observations at Dome C, Antarctica. In: 2nd Antarctic meteorological observation, modelling, and forecasting workshop, Rome, Italy

Argentini S, Mastrantonio G, Petenko I, Pietroni I, Viola A (2011) Use of a high-resolution sodar to study surface-layer turbulence at night. Boundary-Layer Meteorol 1-12. doi:10.1007/s10546-011-9638-9

Arya SPS (1981) Parameterizing the height of the stable atmospheric boundary layer. J Appl Meteorol 20:1192-1202

Asimakopoulos DN, Helmis CG, Michopoulos J (2004) Evaluation of SODAR methods for the determination of the atmospheric boundary layer mixing height. Meteorol Atmos Phys 85:85-92

Astapenko PD (1964) Atmospheric process in the high latitudes of the Southern Hemisphere. Israel Program for Scientific Translations, Jerusalem, $286 \mathrm{pp}$

Batchvarova E, Gryning SE (1990) Applied model for the growth of the daytime mixed layer. Boundary-Layer Meteorol 56:261-274

Batchvarova E, Gryning SE (1994) An applied model for the height of the daytime mixed-layer and the entrainment zone. Boundary-Layer Meteorol 71:311-323

Beyrich F (1994) Mixing-height estimation in the convective boundary layer using sodar data. Boundary-Layer Meteorol 74:1-18

Beyrich F (1997) Mixing height estimation from sodar data-a critical discussion. Atmos Environ 31:39413953

Beyrich F, Weill S (1993) Some aspects of determining the stable boundary layer depth from sodar data. Boundary-Layer Meteorol 63:97-116

Brown EH, Hall FH (1979) Advances in atmospheric acoustics. Rev Geophys Space Phys 16(1):47-110

Carroll JJ (1982) Long-term means and short-term variability of the surface energy balance components at the South Pole. J Geophys Res 87:4277-4286

COST Action 710 (1998) Harmonisation of the pre-processing of meteorological data for atmospheric dispersion models, $431 \mathrm{pp}$

Coulter RL (1990) A case studies of turbulence in the stable nocturnal boundary layer. Boundary-Layer Meteorol 52:75-91

Culf A (1989) Acoustic sounding of the atmospheric boundary layer at Halley, Antarctica. Antarct Sci 1(4):363-372

Emeis S, Schäfer K, Münkel C (2008) Surface-based remote sensing of the mixing-layer height-a review. Meteorol Zeit 17(5):621-630

Georgiadis T, Argentini S, Mastrantonio G, Viola A, Sozzi R, Nardino M (2002) Boundary layer convectivelike activity at Dome Concordia, Antarctica. Il Nuovo Cimento 25:425-431

Gera BS, Argentini S, Mastrantonio G, Viola A (1998) Characteristics of the boundary layer thermal structure in a coastal region of Adelie Land, East Antarctica. Antarct Sci 10:89-98

Gryning SE, Batchvarova E (1990) Analytical model for the coastal internal boundary layer during onshore flow. Q J Roy Meteorol Soc 116:187-203 
Gryning SE, Batchvarova E (1999) Regional heat flux over the NOPEX area estimated from the evolution of the mixed-layer. Agric For Meteorol 98-99:159-167

Holtslag AAM, De Bruin EIF, Pan H-L (1990) A high resolution air mass transformation model for short range weather forecasting. Mon Wea Rev 118:1561-1575

Holzworth CG (1964) Estimates of mean maximum mixing depths in the contiguous United States. Mon Wea Rev 92:235-242

Jauhiainen H, Lehmuskero M (2005) Performance of the Vaisala radiosonde RS92-SGP and Vaisala Digicora sounding system MW31, in the WMO Mauritius radiosonde intercomparison, February 2005, MM210110-A. http://www.vaisala.com/VaisalaDocuments/WhitePapers/VaisalaRadiosondeRS92 inMauritiusIntercomparison.pdf

Kadygrov EN, Pick DR (1998) The potential for temperature retrieval from an angular-scanning single-channel microwave radiometer and some comparisons with in situ observations. Meteorol Appl 5:393-404

Kadygrov EN, Kadygrov VE, Lykov AD, Miller EA, Troitsky AV (2001) Investigation of the atmospheric boundary layer thermodynamics on the base of microwave remote sensing. In: 11th ARM science team proceedings, Atlanta, GA, 8 pp

Kadygrov EN, Koldaev AV, Viazankin AS, Argentini A, Conidi A (2003) A new microwave temperature profiler-first measurements in polar regions. In: 13th ARM science team meeting proceedings, Broomfield, $\mathrm{CO}, 7 \mathrm{pp}$

King JC, Argentini SA, Anderson PS (2006) Contrasts between the summertime surface energy balance and boundary layer structure at Dome C and Halley stations, Antarctica. J Geophys Res 111:D021502. doi:10. 1029/2005JD006130

Krishna TBPS, Rama V, Sharan M, Gopalakrishnan SG, Aditi (2003) Mean structure of the nocturnal boundary layer under strong and weak wind conditions: EPRI case study. J Appl Meteorol 42:952-969

Lee X, Massman W, Law B (2004) Handbook of micrometeorology. Kluwer, Dordrecht, 250 pp

Luers JK (1997) Temperature error of the Vaisala RS90 radiosonde. J Atmos Ocean Technol 14:1520-1532

Luers JK, Eskridge RE (1998) Use of radiosonde temperature data in climate studies. J Clim 11:1002-1019

Malcher J, Kraus H (1983) Low-level-jet phenomena described by an integrated dynamical planetary boundary layer model. Boundary-Layer Meteorol 27:327-343

Mastrantonio G, Malvestuto V, Argentini S, Georgiadis T, Viola A (1999) Evidence of a convective boundary layer developing on the Antarctic Plateau during the summer. Meteorol Atmos Phys 71:127-132

Neff WD (1999) Decadal time scale trends and variability in the tropospheric circulation over the South Pole. J Geophys Res 104:27217-27251

Petenko I, Argentini S, Pietroni I, Viola A (2007) Warming events during winter in Antarctica. In: Proceedings of XI workshop-Italian research on Antarctic atmosphere, pp 119-132

Schwerdtfeger W (1970) The climate of the Antarctic. S. Orvig, climates of the Polar regions, vol 14 of World survey of climatology. Elsevier, Amsterdam, pp 253-255

Schwerdtfeger W (1977) Temperature regime of the South Pole: results of 20 years' observations at Amundsen-Scott Station. Antarct J U S 12:156-159

Seibert P, Beyrich F, Gryning SE, Joffre S, Rasmussen A, Tercier P (2000) Review and intercomparison of operational methods for the determination of the mixing height. Atmos Environ 34:1001-1027

Stearns CR, Wendler G (1988) Research results from Antarctic automatic weather stations. Rev Geophys 26:45-61

Steenelveld GJ, van de Wiel BJH, Holtslag AAM (2007) Diagnostic equations for the stable boundary layer height: evaluation and dimensional analysis. J App Meteorol Climatol 46:212-225

Stone RS (1993) Properties of austral winter clouds derived from radiometric profiles at the South Pole. J Geophys Res 98(D7):12961-12971

Stone RS, Kahl JD (1991) Variations in boundary layer properties associated with clouds and transient weather disturbance at the South Pole during winter. J Geophys Res 96(D3):5137-5144

Stone RS, Dutton GE, DeLuisi JJ (1990) Surface radiation and temperature variations associated with cloudiness at the South Pole. Antarct J Rev 24:230-232

Stull R (1988) An introduction to boundary layer meteorology. Kluwer, Dordrecht, 666 pp

Tomasi C, Petkov B, Benedetti E, Vitale V, Pellegrini A, Dargaud G, De Silvestri L, Grigioni P, Fossat E, Roth WL, Valenziano L (2006) Characterization of the atmospheric temperature and moisture conditions above Dome C (Antarctica) during austral summer and fall months. J Geophys Res 111:D20305. doi:10. 1029/2005JD006976

Van As D, van den Broeke MR, Reijmer C, van De Wal R (2005) The summer surface energy balance of the high Antarctic plateau. Boundary-Layer Meteorol 115:289-317

Venkatram A (1980) Estimating the Monin-Obukhov length in the stable boundary layer for dispersion calculation. Boundary-Layer Meteorol 19:481-485

Yamada T (1978) Prediction of the nocturnal surface inversion height. J Appl Meteorol 18:526-531 
Zilitinkevich S (2002) Third-order transport due to internal waves and non-local turbulence in the stably stratified surface layer. Q J Roy Meteorol Soc 128:913-925

Zilitinkevich S, Calanca P (2000) An extended similarity-theory for the stably stratified atmospheric surface layer. Q J Roy Meteorol Soc 126:1970-1985

Zilitinkevich S, Esau I, Baklanov A (2007) Further comments on the equilibrium height of neutral and stable planetary boundary layers. Q J Roy Meteorol Soc 133(622):265-271 